favour of atoms must be interpreted as evidence for their inner complexity. The presence of absorption and plasma spectra alone suggests that atoms must contain vibrating elements, which we may think of as complexes of balls connected by rods and rubber bands, or as a minute planetary system, or as elastic solids.

Another problem presented by atomic theory concerns the possibility of extending the concepts of our everyday experience to matter on the atomic scale. Every attempt to do so is at best a vicious circle (for we cannot explain the macroscopic property of elasticity merely by reintroducing it at the microscopic level) and at worst a contradiction (for the sensible properties of matter are by definition insensible at the atomic scale).

Hertz responds to this problem with the earliest instance of his picture-theoretical concept of science: we have no choice but to use some sensory pictures in representing the subatomic world to ourselves, he says, and indeed they will involve superfluous, if not contradictory, characteristics; however, these pictures are only ancillary to our system of conceptually defined magnitudes, "which are connected among themselves and with the macroscopic qualities of matter by rigorously defined mathematical relations".

Unfortunately, Hertz's manuscript breaks off before he can conclude the section on ponderable matter. The first section also ends abruptly with a list of questions he did not get round to. Some of these bridge the topics of both parts: does the ether have inertia? Does it have mass? Is it composed of atoms? These questions are of pressing concern, because the idea of reducing forces to actions of the ether will at some point have to explain its mechanical properties. Indeed, one may suppose that the Principles of Mechanics was intended to lay the theoretical foundations for a deeper investigation into these questions. Confronted with the problem of explaining how we might conceive of the "changes in the state of space" required to eliminate forces, Hertz postulated the existence of hidden masses that were, in his view, in better agreement with the demands of reason than the forces they replaced, thereby exercising the very conventional freedom he allows for in Über die Constitution der Materie.

It may seem puzzling that he did not entertain the possibility that space itself is the ground of this change. Had Hertz survived the turn of the century, he would certainly have been an active participant in the debates that resolved that view of gravitation.

David Hyder is at the Max Planck Institute for the History of Science, Wilhelmstrasse 44, 10117

Berlin, Germany. Heinz Lübbig, retired from the Physikalisch-Technische Bundesanstalt, is at Neue Strasse 6, 14163 Berlin, Germany.

\section{Sewage, motorists and more}

\section{The Further Inventions of \\ Daedalus}

by David E. H. Jones

Oxford University Press: 1999. 210 pp.

$\mathfrak{E} 14.99$ ( $p b k$ )

\section{Henry Petroski}

As readers of Nature's News and Views pages know, the pseudonymous inventor Daedalus likes to think out loud about how the world might be made a better place. He is a scientist by training, and as such often reflects upon the world as it is given to us. But he also finds that world wanting and wishes to create things that never were. This is not to say that Daedalus is merely an applied scientist, for he injects a good measure of the engineer's essential ingredient - creativity — into each of his inventions. He imagines a new world, or at least a new artefact, week after week.

Daedalus's tone tends to be light and humorous, an impression often reinforced by the inventor's own cartoons which accompany the 148 articles compiled, revised, augmented and elaborated upon in this collection. Yet he also appears to be deadly serious in his purpose, as evidenced by the pride he takes in reporting that "some $21 \%$ of Daedalus's schemes make some sort of contact with the real world sooner or later".

His proposal for a "combined motorway and linear sewage-treatment system" may be taken as typical. In this case, he begins by noting the importance of crash barriers between opposing lanes of traffic, but recognizes the shortcomings of present designs in damaging cars as well as barriers when they are called into play. He also notes the traditional use of reed-beds to treat flowing sewage. The engineering leap comes in his conceiving of locating marshy reed-beds in the middle of motorways, thus bogging down errant vehicles more or less safely

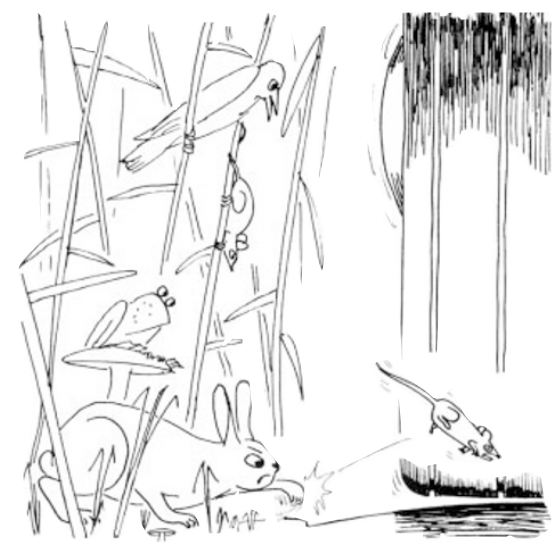

Bogged down in traffic: Daedalus's motorway crash barrier. while providing an efficient use of space in treating sewage. Moreover, the living barrier would be self-repairing.

As an engineer should, Daedalus anticipates how his scheme would succeed or fail in practice. Thus, he recognizes that keeping the water moving over hills and through dales would be essential for maintaining environmental freshness. Being a humorist, Daedalus usually manages to inject a touch of levity into even his most indelicate schemes. In the case of his barrier marsh, he reflects upon the psychological advantages of having a sewage pond between motorists and their anti-motorists. Who but the most incorrigible road hog would not take care to steer clear of the foul-water barrier?

While it is remarkable that Daedalus comes up with a wry idea every week, what is even more remarkable is the fact that he has been doing so for more than 35 years, having composed some 1,800 columns in total. His career began in 1964, when he was asked to contribute something humorous to $\mathrm{New}$ Scientist. In 1988 he moved to The Guardian and Nature. Not too long ago, Daedalus's 500th contribution to Nature, where he now appears exclusively, consisted of an interview with himself(see Nature390, 126-127; 1997). And Daedalus's reflections continue.

Henry Petroski is in the Department of Civil and Environmental Engineering, Duke University, Durham, North Carolina 27708, USA.

\section{Igniting interest in a broad readership}

\section{Encyclopedia of Volcanoes}

edited by Haraldur Sigurdsson et al.

Academic: 1999. 1,400 pp. \$99.95, £69.95

\section{William I. Rose}

Often, the best science is done by people who begin their scientific career in another discipline. Many scientists are fascinated briefly by volcanology, usually by a volcanic eruption that touches their experience. They may think about it, perhaps communicate briefly with someone in the field, and then probably return to whatever they were working on before. The outsider is attracted to volcanology without the intervention of a volcanologist. However, once the specialist gets in the loop, the outsider can become discouraged from taking this interest further.

Our lack of experience in communicating with a broad audience is critical here, and fields such as volcanology, which are undersubscribed compared with some disciplines, pay a high price for the lost opportunity of input from scientists outside the field. We volcanologists realize that our narrow training in petrology, geochemistry and/or geophysics has prepared us inadequately for 


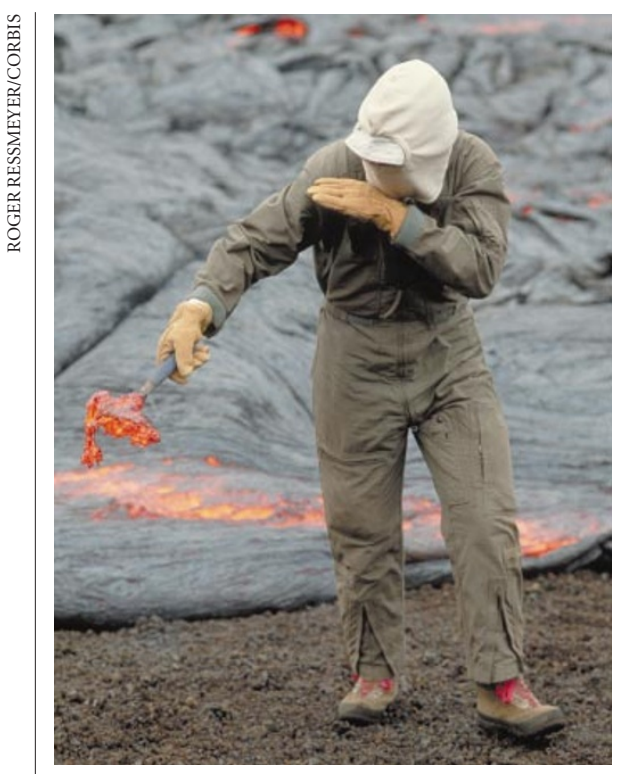

Hot on the job: a volcanologist scoops up molten lava from a flow in Hawaii.

either doing interdisciplinary science well or spreading the word about our work. So we must learn to communicate broadly.

But how can we communicate better as scientists? An attempt to target a general science audience by submitting work to prestigious multidisciplinary journals would probably result in a raft of rejections. Too few of us spend time communicating to general audiences because we fear this will not help us gain stature within our field. Haraldur Sigurdsson, a volcanologist and senior editor of this collection, has led a concerted effort by volcanologists to communicate science more broadly, in this case, to other scientists.

The comprehensive and up-to-date Encyclopedia of Volcanoes represents good, broad scientific writing. Important topics about volcanoes that are rarely addressed in stuffy scientific journals, such as volcanoes in art, literature and film, are to be found here. The book's 83 chapters are written by volcanological scholars and reviewed by their peers. The authors did not 'dumb down' other work, or cut and paste from their scientific journal publications, but instead present difficult science clearly. The problem of jargon, a curse of scientific education, is addressed upfront by a glossary in each chapter. The science presented clearly reveals openings for new investigators.

If you are a scientist who has thought about volcanoes, but haven't followed up your interest, this book should encourage you to go further. The Encyclopedia of Volcanoes is an important experiment that may help to change our writing habits. Even a specialist can learn from writing that reaches out. This kind of communication should be a bigger part of scientists' lives.

William I. Rose is in the Department of Geological Engineering and Sciences, Michigan Technological University, Houghton, Michigan 49931-1295, USA.

\section{A century of physical endeavour}

Quantum Generations: A History of Physics in the Twentieth Century by Helge Kragh

Princeton University Press: 1999. 494 pp. $\$ 29.95, £ 18.95$

\section{Graham Farmelo}

Physicists can be touchy, especially about comments on how they pursue their subject. "Nothing written by historians and philosophers of science about research in physics and how physicists work needs to be taken seriously. They haven't a clue," wrote the veteran physicist Harry Lipkin last year. You could almost hear his colleagues giving him a global round of applause.

You can't blame physicists for feeling a bit sensitive. These days, many of them spend much of their time fighting budget cuts, bewailing diminished career opportunities, defending themselves against charges of arrogance, watching the limelight move to the life sciences. What could be more uplifting for morale than an account of their past 100 years, the most active and successful in their history? The dilemma is: who would be best placed to write it, a physicist or one of those mistrusted historians?

Step forward Helge Kragh, professor of the history of science at Aarhus University in Denmark. When he accepted the invitation to write the book, he thought it would be an easy task, but the experience has made him wiser. In a mildly apologetic introduction, he tells us that he soon realized the impossibility of writing a balanced and comprehensive one-volume account of twentieth-century physics. So he decided to give us a substitute, "a brief and selective account" of what he believes to be the subject's most significant developments. All things considered, he has done a commendable job.

Kragh rightly affirms that twentiethcentury physics began in 1895, on Friday, 8 November, when Wilhelm Röntgen first observed X-rays. To quote this as the date of the discovery of X-rays would be "simplistic" (one of Kragh's favourite words), because the significance of Röntgen's observations became clear only during the following weeks. As Kragh repeatedly makes clear in Quantum Generations, discovery is usually a process, not an event.

A more conventional chronology would cite Max Planck's presentation of his first paper on quantum theory on 14 December 1900 as the beginning of the past century of physics. Kragh's thorough account of Planck's work will be news to the overwhelming majority of physicists who believe the oversimplified accounts of early quantum history that are continually recycled in their textbooks. Contrary to widespread belief among physicists, it is far from clear whether Planck initially recognized that he had quantized the energy of individual atoms; that step was first taken a few years later by Albert Einstein, whom many historians regard as quantum theory's first true pioneer and advocate.

Kragh rightly credits Einstein as being the leading light of relativity theory. Once again, many physicists will be intrigued by the parts of Kragh's account that are not usually included in physics texts. He tellingly quotes the French mathematician Henri Poincaré, writing shortly before Einstein wrote his first paper on relativity in 1905: "The laws of physical phenomena must be the same for a 'fixed' observer as for an observer who has a uniform motion relative to him ... there must arise an entirely new kind of dynamics, which will be characterised above all by the rule that no velocity can exceed that of light".

One of the strengths of Quantum Generations is its inclusion of a huge amount of clearly referenced information on the growth of physics from 1900 to the present. Kragh points out that the number of physicists has grown during this period from around 1,500 to 100 times that number, with a commensurate increase in the number of publications. He broadly agrees that the subject has grown exponentially, although he suggests that such growth may apply only after 1920.

By then, Einstein had formulated his general theory of relativity, but this attracted very few followers compared with the growing number of scientists who were working on quantum theory. Kragh's coverage of the development of quantum theory into fully fledged quantum mechanics is, for my money, disappointing. He gives us the facts, but does not do justice to the revolutionary changes these pioneers made to the way scientists - and philosophers - think about the Universe. The story is worth a good deal more space than Kragh allows.

By the 1930s, the leadership of physics passed from Germany to the United States. Kragh, always strong on the international dimensions of his story, points out that this change in leadership occurred even before the arrival of the physicists who had fled Germany and Italy. Several of the refugees participated in the Manhattan project, whose technological success changed forever the relationship between scientists, the government and the military in the United States. Before the Second World War, the total federal spending of the US government on basic physics research was only $\$ 1$ million. By the 1980s, President Ronald Reagan was prepared to spend \$26 billion on the mercifully ill-fated Star Wars initiative, setting some of the participating physicists temporarily awash with money. 